\title{
The structure of the vascular system of the septomarginal trabecula in the heart of an adult
}

\author{
Miłosz Zajączkowski ${ }^{1, A-F}$, Adam Kosiński, ${ }^{1, A-F}$, Marek Grzybiak ${ }^{1, A, E, F}$, Rafał Kamiński ${ }^{1, B, C}$, \\ Agata Kaczyńska ${ }^{1, B, C, E}$, Stanisław Zajączkowski2, ${ }^{2, D, E}$, Ewa Nowicka ${ }^{1, B, C}$ \\ ${ }^{1}$ Department of Clinical Anatomy, Medical University of Gdansk, Poland \\ ${ }^{2}$ Department of Physiology, Medical University of Gdansk, Poland \\ A - research concept and design; $\mathrm{B}$ - collection and/or assembly of data; $\mathrm{C}$ - data analysis and interpretation; \\ $\mathrm{D}$ - writing the article; $\mathrm{E}$ - critical revision of the article; $\mathrm{F}$ - final approval of the article
}

Address for correspondence

Miłosz Zajączkowski

E-mail: milosz@gumed.edu.pl

Funding sources

None declared

Conflict of interest

None declared

Received on January 15, 2016

Reviewed on November 14, 2016

Accepted on January 27, 2017

\section{Abstract}

Background. In cardiology, the paths of the arteries penetrating the septomarginal trabecula (SMT) are especially important. They provide blood supply to the apparatus of the right atrioventricular orifice and often form anastomoses with the system of the right coronary artery. Despite this, only a few publications discuss the morphological aspect of the septomarginal trabecula, and available histological analyses seldom deal with its blood supply.

Objectives. The aim of this study was to analyze the vessel structure of the septomarginal trabecula in terms of the variability of the area of the cross-section of the lumen and the muscular layer of the artery.

Material and methods. The study was carried out on the material of 50 human hearts from adults of both sexes. The material was divided into 4 morphological types. Histological examinations were conducted by means of classic staining methods.

Results. At the initial cross-section of the septomarginal trabecula, the area of the cross-section increased to half of the length of the trabecula, and then it started to decrease. This is connected with the thickening of the inner muscular layer of the artery, which proportionally takes up more area of the cross-section of the whole artery of the SMT. The total area of the cross-section of all vessels in both types examined was also the largest in the middle part of the SMT. Furthermore, the results of this study confirm the presence of a connection between both systems of coronary arteries.

Conclusions. As the septomarginal trabecula passes through the lumen of the right ventricle, its arteries become exposed to the influence of the factors which may evoke a biological response from the walls of this vessel, causing the thickening of the muscular layer and, as a result, of the section of the whole artery, in particular its middle part.

Key words: morphology, human heart, coronary arteries, heart ventricle, septomarginal trabecula

DOI

$10.17219 /$ acem $/ 68692$

\section{Copyright}

Copyright by Author(s)

This is an article distributed under the terms of the

Creative Commons Attribution Non-Commercial License

(http://creativecommons.org/licenses/by-nc-nd/4.0/) 


\section{Introduction}

Among the wide network of the trabeculae of the right ventricle of the human heart, the septomarginal trabecula (SMT) plays a particularly important role. Its structure contains vessels supplying the valve apparatus of the right ventricle, which often form anastomoses with the right coronary artery. Moreover, within the trabecula there are often branches of the right offshoot of the bundle of His.

Despite this, only a few publications present the morphological aspect of the SMT. Available histological analyses are devoted to the issues of the ratio of muscle tissue to connective tissue, as well as the presence of fibers of the conduction system, so they seldom discuss its blood supply. Therefore, a detailed analysis of the arterial blood supply of this structure seems to have a clinical significance. The dynamic development of cardiac surgery and invasive diagnostic and treatment methods reveal the need for more detailed knowledge of the positions of vessels in various structures inside the heart cavities. Such knowledge may lead to procedures with optimal saving of the heart structures and to the prevention of potential complications.

The aim of this study was to analyze the vessel structure of the septomarginal trabecula in terms of the variability of the area of the cross-section of the lumen and the muscular layer.

\section{Material and methods}

The study was carried out on the material of $50 \mathrm{hu}$ man hearts fixed in a solution of formalin and ethanol. The hearts, in which no lesions or developmental defects were found macroscopically during the section, came from adults (18-76 years old) of both sexes. The material was divided into 4 morphological types according to the classification suggested by Kosiński et al. ${ }^{1}$ The analysis was performed on the basis of the observation of the cross-sections of the SMT divided into 10 equal sections (levels) (Fig. 1). The histological examination was conducted by means of classic staining methods (hematoxylin eosin, van Gieson's stain with Goldner's modification) under a stereo-microscope (MN 800 Series; Opta-Tech, Warszawa, Poland) with Moticam 2000 2.0M camera (Motic Incorporation Ltd., Hong Kong) and the use of the Motic Images Plus v. 2.0 2006 (Motic China Group Co., Ltd., Xiamen, China) computer program.

The majority of variables did not have a normal distribution and were analyzed by means of non-parametric tests. The $1^{\text {st }}$ tested hypothesis which stated that the probability distributions were the same in all examined groups was rejected (the Friedman test; $\mathrm{p}<0.001$ ). Taking the natural structure of the examined material into consideration, the results of this test were not included in the paper, and post hoc procedures were performed. When performing these

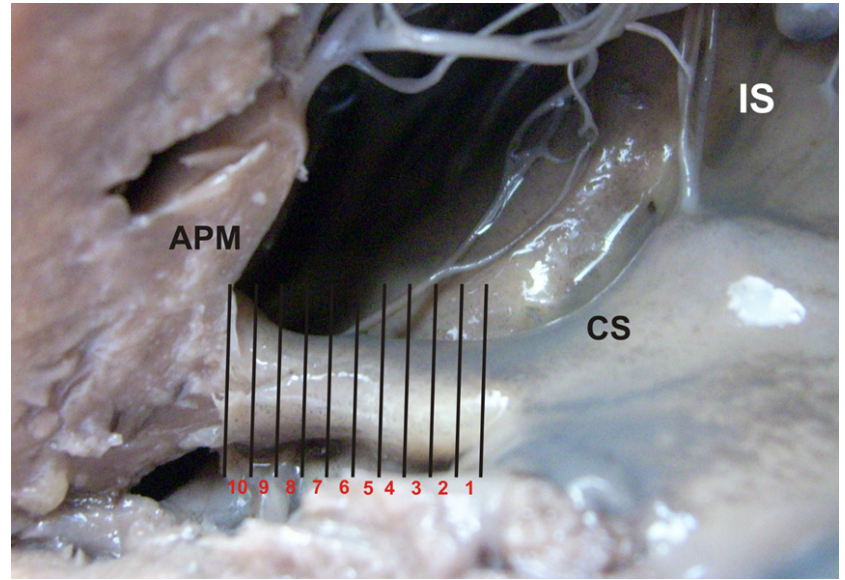

Fig. 1. The division of the SMT into 10 levels. The view of the right ventricle AMP - anterior papillary muscle; CS - supraventricular crest; IS - intraventricular septum.

procedures, the Mann-Whitney test for paired samples was used (which is, of course, equivalent to the Wilcoxon test for paired samples in this case). A p-value $<0.05$ was considered to be statistically significant. The statistical analyses were performed using R v. 2.15.1. ${ }^{2}$

\section{Results}

During the study, 4 morphological types of the SMT were confirmed. The division into these types regards the paths of the SMT penetrating through the lumen of the right ventricle and the relation of SMT to the anterior papillary muscle. In type I, the SMT, which varied with respect to thickness, constituted a homogenous structure not directly connected with the anterior papillary muscle. In types II and III, the SMT constituted a homogenous structure undivided by the anterior papillary muscle. The difference from type I lies in a close connection of the base of the anterior papillary muscle with the anterior wall of the ventricle, as well as its direct connection with the trabecula. Type II is a tangent connection of the trabecula and the anterior papillary muscle or their permanent integration to some degree. However, in type III, the base of the muscle attached to the anterior wall was closely connected with the peripheral end of the SMT. Type IV included cases in which 2 parts of the SMT could be distinguished. The first is septal-papillary part that connects the intraventricular septum and the anterior papillary muscle. The second one is the papillary-marginal part located between the anterior papillary muscle and the anterior wall of the right ventricle.

The frequency of the occurrence of particular types of SMT is presented in Table 1.

The results presented in this study include the 2 most numerous morphological types: type III and IV.

The main vascularization of the SMT is formed by its main artery, which offshoots from one of the septal 
Table 1. Frequency of occurrence of particular types of SMT

\begin{tabular}{|l|c|c|}
\hline \multicolumn{1}{|c|}{ Type } & Number & $\%$ \\
\hline I & 3 & 6 \\
\hline II & 6 & 12 \\
\hline III & 24 & 48 \\
\hline IV & 17 & 34 \\
\hline Total & 50 & 100 \\
\hline
\end{tabular}

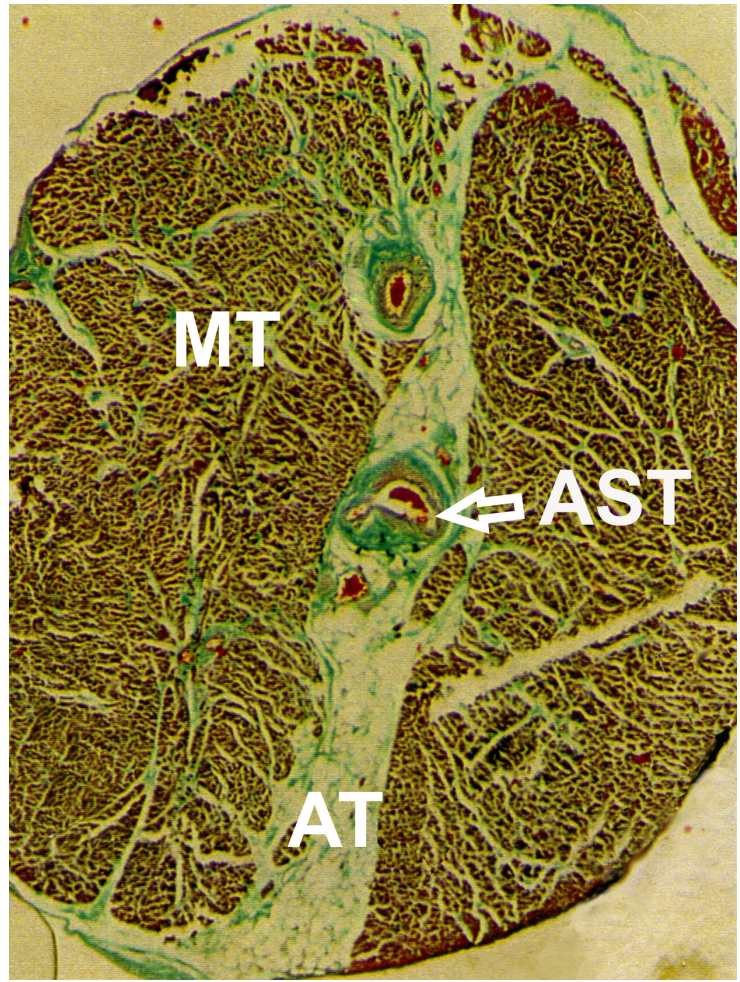

Fig. 2. The cross-section of the SMT

Masson-Goldner staining; magnification $\times 2$; AST - the artery of the SMT; AT - adipose tissue; MT - muscle tissue.

arteries. On the cross-section of the trabecula, its main artery is most often found in a central location (Fig. 2).

The artery takes the peripheral position when it approaches the anterior papillary muscle (Fig. 3).

The main artery of the SMT is always significantly larger than other SMT arteries (Fig. 4).

In some cases, the artery may comprise a substantial part of the whole cross-section of the SMT (Fig. 5).

\section{The area of the cross-section of the artery of the septomarginal trabecula}

Our results indicate that in type III, the area of the crosssection of the artery of the SMT increases only on 4 levels. On the next levels, it slightly decreases or remains at the same value. On the $4^{\text {th }}$ level, the examined artery assumes the highest median and max values. The artery of the SMT is found to first widen successively until it reaches its peak value at level 4 , and then its area is getting smaller (Table 2).

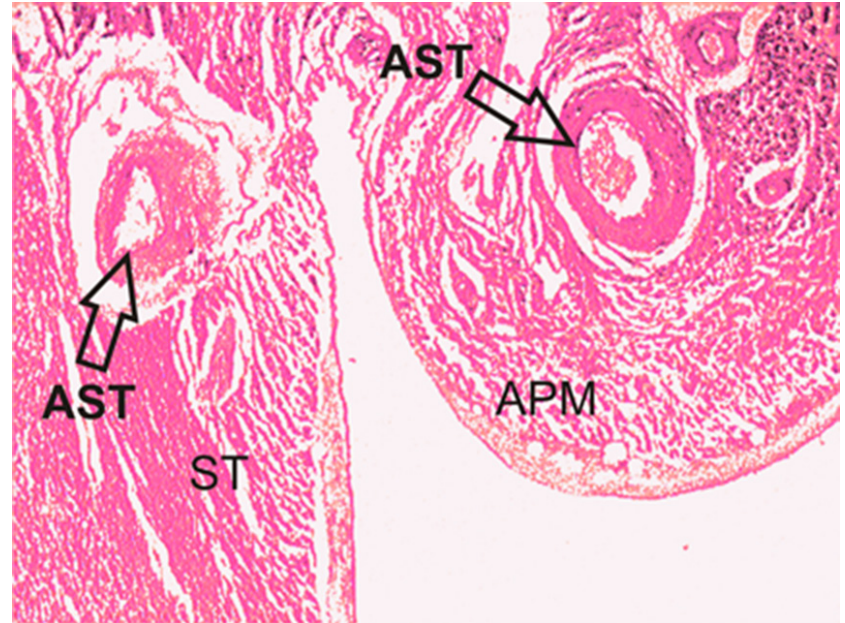

Fig. 3. The cross-section of the SMT and the anterior papillary muscle

Hematoxylin and eosin stain; magnification $\times 4$; APM - anterior papillary muscle; AST - the artery of the SMT.

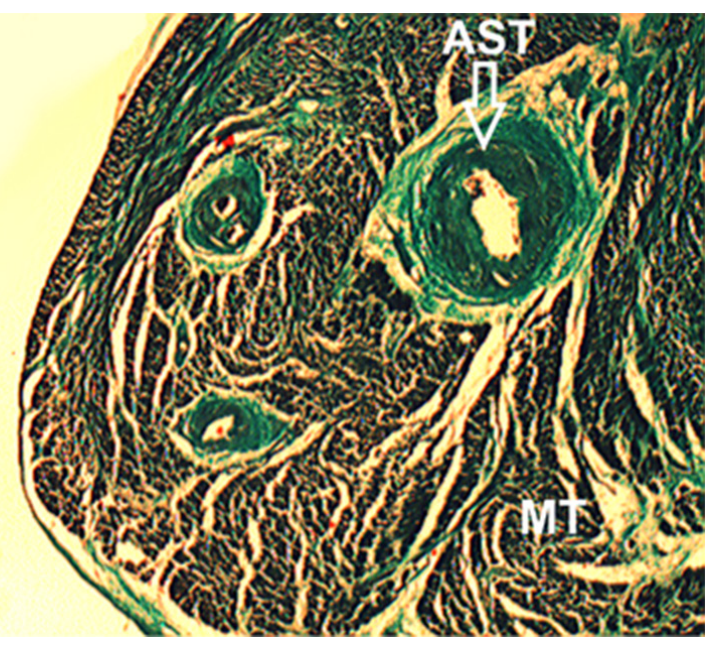

Fig. 4. The cross-section of the SMT

Masson-Goldner staining; magnification $\times 4$; MT - muscle tissue; AST - the artery of the SMT.

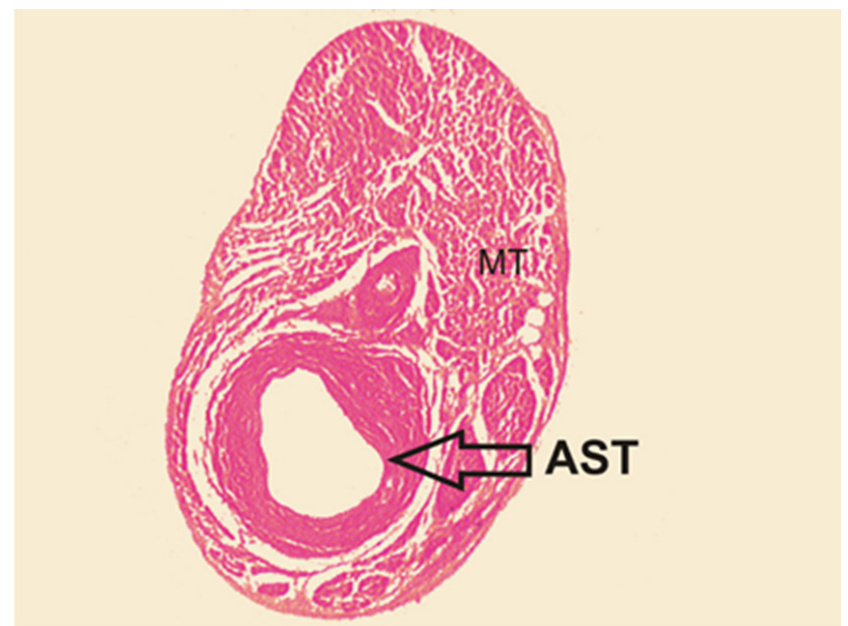

Fig. 5. The cross-section of the SMT

Hematoxylin and eosin stain; magnification $\times 4$; AST - the artery of the SMT; MT - muscle tissue. 
Table 2. Type III: The values of statistical characteristics of the area of the cross-section of the artery of the SMT on 10 levels of the trabecula

\begin{tabular}{|c|c|c|c|}
\hline \multirow{2}{*}{ Level } & $\begin{array}{c}\text { Median } \\
{\left[\mathrm{mm}^{2}\right]}\end{array}$ & $\begin{array}{c}\text { Min } \\
{\left[\mathrm{mm}^{2}\right]}\end{array}$ & $\begin{array}{c}\text { Max } \\
{\left[\mathrm{mm}^{2}\right]}\end{array}$ \\
\hline 1 & $0.241^{\mathrm{a}}$ & 0.04 & 0.57 \\
\hline 2 & $0.238^{\mathrm{b}, \mathrm{c}}$ & 0.047 & 0.584 \\
\hline 3 & $0.272^{\mathrm{d}}$ & 0.057 & 0.667 \\
\hline 5 & $0.278^{\mathrm{e}, \mathrm{f}}$ & 0.045 & 0.732 \\
\hline 6 & 0.25 & 0.044 & 0.594 \\
\hline 8 & 0.27 & 0.056 & 0.536 \\
\hline 9 & 0.252 & 0.066 & 0.555 \\
\hline 10 & 0.263 & 0.047 & 0.591 \\
\hline
\end{tabular}

a 1 vs $4, p=0.03 ;{ }^{b} 2$ vs $3, p=0.04 ;{ }^{c} 2$ vs $4, p=0.01 ;{ }^{d} 3$ vs $4, p=0.04$;

e 4 vs $7, p=0.04 ;^{f} 4$ vs $9, p=0.04$.

Table 3. Type IV: The values of statistical characteristics of the area of the cross-section of the artery of the SMT on 10 levels of the trabecula

\begin{tabular}{|c|c|c|c|}
\hline \multirow{2}{*}{ Level } & $\begin{array}{c}\text { Median } \\
{\left[\mathrm{mm}^{2}\right]}\end{array}$ & $\begin{array}{c}\text { Min } \\
{\left[\mathrm{mm}^{2}\right]}\end{array}$ & $\begin{array}{c}\text { Max } \\
{\left[\mathrm{mm}^{2}\right]}\end{array}$ \\
\hline 1 & 0.204 & 0.045 & 0.732 \\
\hline 2 & $0.21^{\mathrm{a}, \mathrm{b}, \mathrm{c}}$ & 0.043 & 0.502 \\
\hline 3 & 0.206 & 0.047 & 0.5 \\
\hline 5 & 0.19 & 0.049 & 0.63 \\
\hline 6 & 0.216 & 0.047 & 0.62 \\
\hline 7 & $0.218^{\mathrm{d}}$ & 0.043 & 0.772 \\
\hline 9 & $0.215^{\mathrm{e}}$ & 0.051 & 0.653 \\
\hline 10 & 0.227 & 0.068 & 0.592 \\
\hline
\end{tabular}

a 2 vs $3, p=0.04 ;{ }^{b} 2$ vs $5, p=0.04 ;{ }^{c} 2$ vs $6, p=0.04{ }^{d}{ }^{d} 6$ vs $9, p=0.04 ;$ e 7 vs $9, p=0.04$

The results indicate that the area of the cross-section of the artery of the SMT in type IV is subject to fluctuations over the whole length, with a distinct gradual decrease in the area from level 6 to level 9. The median value of the area of the artery of the trabecula increases statistically significantly between level 2 and levels 3, 5 and 6 (Table 3).

\section{Total area of the cross-section of all arteries of the septomarginal trabecula}

The results indicate that in type III, the total area of the cross-section of all arteries of the trabecula increases statistically significantly on the first 5 levels. From that point, certain fluctuations occur: the area slightly decreases or slightly increases. Statistical analyses have also revealed a significant decrease of the studied value from level 4 to level 9 (Table 4).
Table 4. Type III: The values of statistical characteristics of the total area of the cross-section of all arteries of the SMT on 10 levels of the trabecula

\begin{tabular}{|c|c|c|c|}
\hline Level & $\begin{array}{c}\text { Median } \\
{\left[\mathrm{mm}^{2}\right]}\end{array}$ & $\begin{array}{c}\text { Min } \\
{\left[\mathrm{mm}^{2}\right]}\end{array}$ & $\begin{array}{c}\text { Max } \\
{\left[\mathrm{mm}^{2}\right]}\end{array}$ \\
\hline 1 & $0.259^{\mathrm{a}, \mathrm{b}, \mathrm{c}, \mathrm{d},}$ & 0.066 & 1.085 \\
\hline 2 & $0.293^{\mathrm{e}}$ & 0.071 & 1.052 \\
\hline 3 & 0.318 & 0.082 & 1.034 \\
\hline 4 & $0.33^{\mathrm{f}}$ & 0.067 & 1.031 \\
\hline 5 & 0.339 & 0.068 & 1.022 \\
\hline 7 & 0.343 & 0.081 & 1.035 \\
\hline 8 & 0.29 & 0.092 & 1.088 \\
\hline 9 & 0.3 & 0.062 & 1.13 \\
\hline 10 & 0.284 & 0.058 & 1.139 \\
\hline
\end{tabular}

a 1 vs $2, p=0.05 ;^{b} 1$ vs $3, p=0.05$ c $^{c} 1$ vs $4, p=0.04{ }^{d} 1$ vs $5, p=0.03$ e $^{2}$ vs 4 , $p=0.04{ }^{f} 4$ vs $9, p=0.03$.

Table 5. Type IV: The values of statistical characteristics of the total area of the cross-section of all arteries of the SMT on 10 levels of the trabecula

\begin{tabular}{|c|c|c|c|}
\hline Level & $\begin{array}{c}\text { Median } \\
{\left[\mathrm{mm}^{2}\right]}\end{array}$ & $\begin{array}{c}\text { Min } \\
{\left[\mathrm{mm}^{2}\right]}\end{array}$ & $\begin{array}{c}\text { Max } \\
{\left[\mathrm{mm}^{2}\right]}\end{array}$ \\
\hline 1 & $0.246^{\mathrm{a}}$ & 0.045 & 0.748 \\
\hline 2 & $0.239^{\mathrm{b}, \mathrm{c}, \mathrm{d}, \mathrm{e}, \mathrm{f}, \mathrm{g}}$ & 0.043 & 0.678 \\
\hline 3 & $0.229^{\mathrm{h}}$ & 0.05 & 0.66 \\
\hline 4 & $0.231^{\mathrm{i}}$ & 0.053 & 0.82 \\
\hline 5 & 0.225 & 0.048 & 0.804 \\
\hline 7 & 0.232 & 0.043 & 0.839 \\
\hline 8 & $0.241^{j}$ & 0.053 & 0.699 \\
\hline 9 & 0.249 & 0.07 & 0.616 \\
\hline 10 & 0.233 & 0.075 & 0.668 \\
\hline
\end{tabular}

${ }^{a} 1$ vs $5, p=0.04 ;{ }^{b} 2$ vs $3, p=0.03 ;{ }^{c} 2$ vs $4, p=0.02 ;{ }^{d} 2$ vs $5, p=0.03$

e 2 vs $6, p=0.03 ;^{f} 2$ vs $7, p=0.02 ;{ }^{g} 2$ vs $8, p=0.04 ;^{\text {h }} 3$ vs $7, p=0.03$; i 4 vs $7, p=0.03 ;$ j 7 vs $9, p=0.02$.

Our results indicate that in type IV, the total area of the cross-section of all arteries of the trabecula increases statistically significantly between level 2 and level 8. A gradual increase in the median value of this area from level 5 to level 8 of the trabecula may be observed (Table 5).

\section{The number of arteries on the cross-section of the septomarginal trabecula}

When particular levels are grouped into sections corresponding to the beginning, middle and end of the trabecula, statistical differences among all groups can be seen in type III. The number of arteries increases successively from the beginning to the end of the trabecula (Fig. $6 \mathrm{~A}$ ). However, in type IV, statistically significant differences occurred between group 1 and groups 2 and 3 . The number 
of arteries increases from the beginning to the end of the trabecula (Fig. 6 B).

Type III - statistically significant differences, on the level of $\mathrm{p}<0.05$ (the Wilcoxon test), between levels $1-3$ and $4-7 ; 4-7$ and $8-10 ; 1-3$ and 8-10.

Type IV - statistically significant differences, on the level of $\mathrm{p}<0.05$ (the Wilcoxon test), between levels $1-3$ and $4-7 ; 1-3$ and $8-10$.

\section{The ratio of the area of the cross-section of all the arteries of the septomarginal trabecula to their number}

When particular levels are grouped into sections corresponding to the beginning, middle and end of the trabecula, then statistical differences among all 3 groups can be noticed in type III (F ig. 7 A). However, in type IV, statistically significant differences occurred between the end and the beginning, and the middle parts of the trabecula (Fig. 7 B).

Type III - statistically significant differences, on the level of $\mathrm{p}<0.05$ (the Wilcoxon test), between levels $1-3$ and $4-7 ; 1-3$ and $8-10 ; 4-7$ and $8-10$.

Type IV - statistically significant differences, on the level of $\mathrm{p}<0.05$ (the Wilcoxon test), between levels $1-3$ and $8-10 ; 4-7$ and $8-10$.

\section{The area of the cross-section of the muscular layer of the septomarginal trabecula}

The results indicate that in type III, the area of the crosssection of the muscular layer of the SMT shows certain dynamics of behavior. Although it is not statistically significant, the median value increases up to the middle of the trabecula (Table 6).

The results of this study show the following tendency: in type IV, the median value of the area of the cross-section of the muscular layer gradually increases up to level 7, and then decreases up to the end of the trabecula (Table 7).

\section{The ratio of the area of the cross-section of the muscular layer of the SMT to the area of the cross-section of the artery of the SMT}

Our results revealed an increase in the median value of the ratio of the area of the cross-section of the muscular layer to the area of the cross-section of the artery in type III from level 2 to level 6 . The median is smaller at the beginning than at the end of the trabecula (Table 8 ).

The results indicate that in type IV, the median value of the ratio of the area of the cross-section of the muscular layer to the area of the cross-section of the artery increases from level 3 to level 6 of the trabecula. The median is smaller at the beginning than at the end of the trabecula (Table 9).

When particular levels are grouped into sections corresponding to the beginning, middle and end of the trabecula, in type III, statistically significant differences can be found between the end and the beginning, and the middle of the trabecula (Fig. 8 A). However, in type IV there is a statistically significant difference between the end and the beginning of the trabecula (Fig. 8 B).
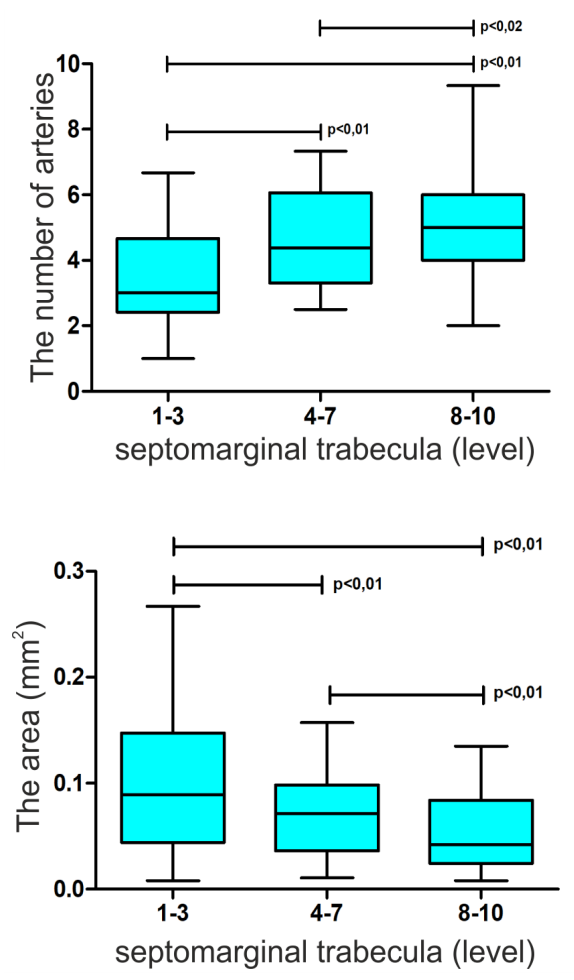
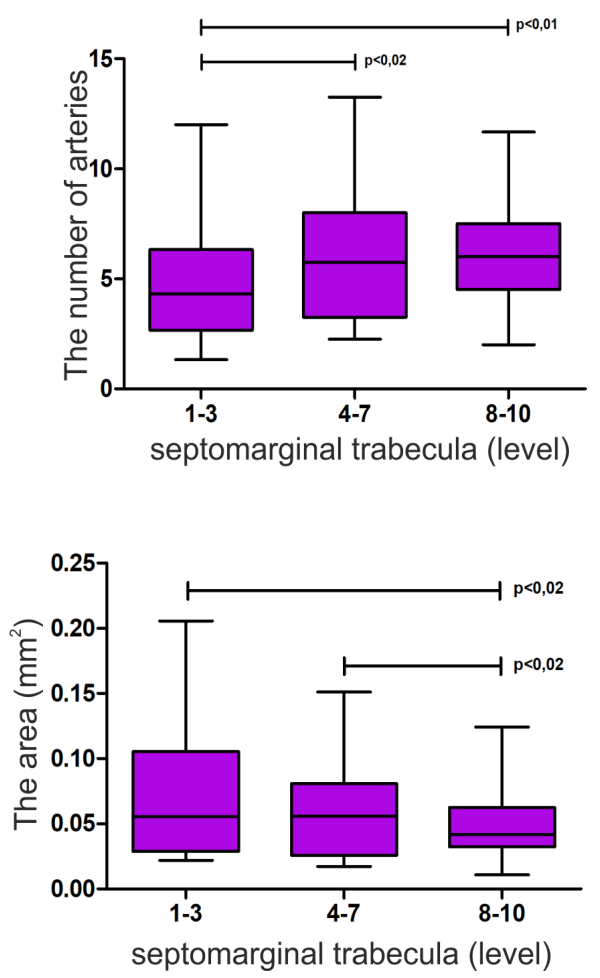

Fig. 6. The number of arteries on the crosssection of the SMT in 3 groups of different distance from the trabecula (the results are presented as a median and an interquartile range)

A - type III; B - type IV.

Fig. 7. The ratio of the area of the crosssection of all arteries of the SMT to their number in 3 groups of different distance from the trabecula (the results are presented as a median and an interquartile range) A - type III; B - type IV. 
Table 6. Type III: The values of statistical characteristics of the area of the cross-section of the muscular layer of the artery of the SMT on 10 levels of the trabecula

\begin{tabular}{|c|c|c|c|}
\hline Level & $\begin{array}{c}\text { Median } \\
{\left[\mathrm{mm}^{2}\right]}\end{array}$ & $\begin{array}{c}\text { Min } \\
{\left[\mathrm{mm}^{2}\right]}\end{array}$ & $\begin{array}{c}\text { Max } \\
{\left[\mathrm{mm}^{2}\right]}\end{array}$ \\
\hline 1 & 0.127 & 0.028 & 0.374 \\
\hline 2 & 0.146 & 0.035 & 0.362 \\
\hline 3 & 0.152 & 0.044 & 0.409 \\
\hline 4 & 0.16 & 0.035 & 0.413 \\
\hline 5 & 0.159 & 0.03 & 0.403 \\
\hline 6 & 0.14 & 0.039 & 0.366 \\
\hline 8 & 0.138 & 0.04 & 0.419 \\
\hline 9 & 0.167 & 0.03 & 0.418 \\
\hline 10 & 0.14 & 0.04 & 0.432 \\
\hline
\end{tabular}

Table 7. Type IV: The values of statistical characteristics of the area of the cross-section of the muscular layer of the artery of the SMT on 10 levels of the trabecula

\begin{tabular}{|c|l|l|l|}
\hline Level & $\begin{array}{c}\text { Median } \\
{\left[\mathrm{mm}^{2}\right]}\end{array}$ & $\begin{array}{c}\text { Min } \\
{\left[\mathrm{mm}^{2}\right]}\end{array}$ & $\begin{array}{c}\text { Max } \\
{\left[\mathrm{mm}^{2}\right]}\end{array}$ \\
\hline 1 & 0.103 & 0.025 & 0.411 \\
\hline 2 & 0.113 & 0.024 & 0.37 \\
\hline 3 & 0.119 & 0.024 & 0.379 \\
\hline 5 & 0.113 & 0.024 & 0.452 \\
\hline 6 & 0.121 & 0.022 & 0.463 \\
\hline 7 & 0.136 & 0.022 & 0.612 \\
\hline 9 & 0.152 & 0.023 & 0.519 \\
\hline 10 & 0.148 & 0.031 & 0.467 \\
\hline
\end{tabular}

Table 8. Type III: The statistical values of the ratio of the area of the crosssection of the muscular layer of the artery of the SMT to the area of the cross-section of its artery

\begin{tabular}{|c|l|l|l|}
\hline Level & $\begin{array}{c}\text { Median } \\
{\left[\mathrm{mm}^{2}\right]}\end{array}$ & $\begin{array}{c}\text { Min } \\
{\left[\mathrm{mm}^{2}\right]}\end{array}$ & $\begin{array}{c}\text { Max } \\
{\left[\mathrm{mm}^{2}\right]}\end{array}$ \\
\hline 1 & 0.637 & 0.322 & 0.929 \\
\hline 2 & $0.608^{\mathrm{a}}$ & 0.333 & 0.918 \\
\hline 3 & $0.623^{\mathrm{b}, \mathrm{c}, \mathrm{d}}$ & 0.388 & 0.915 \\
\hline 4 & $0.626^{\mathrm{e}, \mathrm{f}, \mathrm{g}}$ & 0.346 & 0.93 \\
\hline 5 & $0.641^{\mathrm{h}}$ & 0.351 & 0.924 \\
\hline 7 & 0.646 & 0.417 & 0.927 \\
\hline 8 & 0.635 & 0.363 & 0.935 \\
\hline 9 & 0.662 & 0.406 & 0.929 \\
\hline 10 & 0.643 & 0.44 & 0.926 \\
\hline
\end{tabular}

a 2 vs $8, p=0.04 ;{ }^{b} 3$ vs $8, p=0.02$; $^{c} 3$ vs $9, p=0.05 ;$ d 3 vs $10, p=0.05$; e 4 vs $8, p<0.01 ; f$ vs $9, p=0.01 ; 94$ vs $10, p=0.03 ;{ }^{h} 5$ vs $8, p=0.04$.

Table 9. Type IV: The statistical values of the ratio of the area of the crosssection of the muscular layer of the artery of the SMT to the area of the cross-section of its artery

\begin{tabular}{|c|l|l|l|}
\hline Level & $\begin{array}{c}\text { Median } \\
{\left[\mathrm{mm}^{2}\right]}\end{array}$ & $\begin{array}{c}\text { Min } \\
{\left[\mathrm{mm}^{2}\right]}\end{array}$ & $\begin{array}{c}\text { Max } \\
{\left[\mathrm{mm}^{2}\right]}\end{array}$ \\
\hline 1 & 0.621 & 0.407 & 0.894 \\
\hline 2 & 0.614 & 0.391 & 0.88 \\
\hline 3 & 0.594 & 0.306 & 0.871 \\
\hline 4 & $0.621^{\mathrm{a}}$ & 0.322 & 0.84 \\
\hline 5 & $0.644^{\mathrm{b}}$ & 0.348 & 0.855 \\
\hline 6 & 0.651 & 0.47 & 0.89 \\
\hline 8 & 0.65 & 0.44 & 0.888 \\
\hline 9 & 0.635 & 0.409 & 0.882 \\
\hline 10 & 0.675 & 0.481 & 0.904 \\
\hline
\end{tabular}

a 4 vs $10, p=0.04 ;^{b} 5$ vs $10, p=0.05$

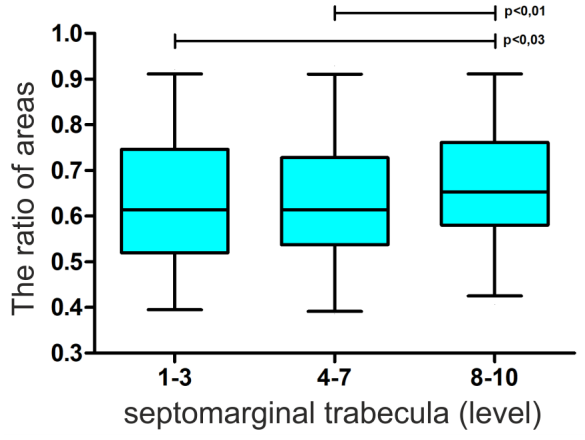

Type III - statistically significant differences, on the level of $\mathrm{p}<0.05$ (the Wilcoxon test), between levels 1-3 and $8-10 ; 4-7$ and $8-10$.

Type IV - statistically significant differences, on the level of $\mathrm{p}<0.05$ (the Wilcoxon test), between levels 1-3 and $8-10$.

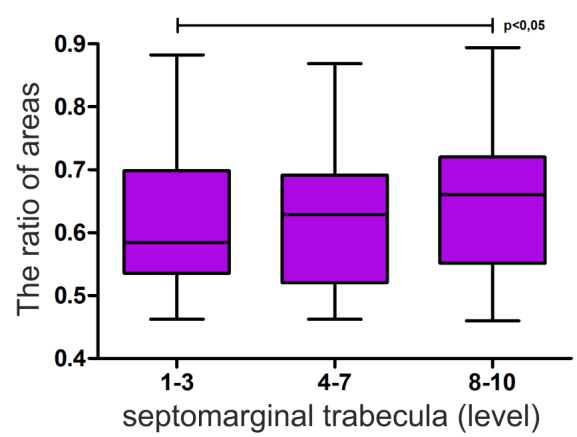

Fig. 8. The ratio of the area of the crosssection of the muscular layer of the SMT to the area of the cross-section of the artery of the SMT in 3 groups of different distance from the trabecula (the results are presented as a median and an interquartile range)

A - type III; B - type IV.

\section{Discussion}

There is hardly a substantial body of knowledge on the blood supply of the septomarginal trabecula. Gross was the first researcher to observe the constant occurrence of the artery of the SMT (ramus limbi dextri) in 1921, and other 
researchers have confirmed its presence. ${ }^{3-12}$ It is often described as a branch of one of the septal arteries, which branches off from the anterior descending artery. While studying the position of the artery of the trabecula, Reig et al. noticed that in 20 cases $(71 \%)$ this artery originated in the $2^{\text {nd }}$ anterior septal artery, in 5 cases $(18 \%)$ in the $1^{\text {st }}$ anterior septal artery, and in 2 cases $(7 \%)$ in the $3^{\text {rd }}$ one. ${ }^{6}$ However, in 1 case (4\%) they confirmed the presence of 2 arteries in the trabecula and both of them originated in the $2^{\text {nd }}$ and $3^{\text {rd }}$ anterior septal artery. They described 2 possible paths of the arteries which mark the beginning of the artery of the SMT (in relation to a short heart axis). In 19 out of 28 examined cases, there was a horizontal path. This type included arteries that originated from the $1^{\text {st }}$ anterior septal artery and the majority of vessels originating from the $2^{\text {nd }}$ anterior septal artery.

They proceeded through the site of the septal papillary muscle in a subendocardial position and branched off to it, as well as toward the apex of the heart. Then, they passed through the muscle accompanying and providing blood supply to the right branch of the bundle of His. Both of these structures followed the paths through the whole length of the SMT, and the SMT artery was positioned deeper until it reached the base of the anterior papillary muscle. ${ }^{6}$ The same location of the artery of the SMT was observed in our study; it ran mainly in the central part of the cross-section of the trabecula (Fig. 2). Nevertheless, it took a peripheral position when it approached the anterior papillary muscle (Fig. 3). However, according to Melo et al., this artery is located in the lower part. ${ }^{4}$

Reig et al. state that the $2^{\text {nd }}$ path which arteries may follow to the SMT is an oblique path. It extends from the right side of the SMT toward the apex of the heart until it reaches the place where the SMT separates from the septum. From that point on, it displays the same topography and relations as in the case of the horizontal path. The arteries following this path may also branch off to the septal papillary muscle and the initial part of the right branch of the bundle of His. This type of path was found in the arteries of the SMT originating mainly from the $3^{\text {rd }}$ and sometimes from the the $2^{\text {nd }}$ septal artery. ${ }^{6}$

Melo et al., after examining 30 human hearts, characterized the number and trajectory of the major septal arteries which serve as the origin of the SMT artery. They confirmed the presence of 210 septal arteries, which means on average 7 arteries per heart. One major septal artery was found in $90 \%$ (27) of hearts, 2 were found in 7\% (2) of hearts and $3 \%$ (1) of the hearts had 3 arteries, from which 1 would always enter the SMT in its lower part. ${ }^{4}$

The knowledge of the topography of the arteries of the SMT, as well as of the paths of the vessels leading to it, is very important for every cardiac surgeon. Procedures can be carried out with a maximum saving rate of the structures of the right ventricle and with the prevention of possible complications (e.g., during the application of a surgical method requiring incisions in the area of the septum, such as the correction of the Tetralogy of Fallot - TOF). The topography of the abovementioned arteries may also be assessed with the use of angiographic techniques. Therefore, in vivo diagnostics deserves special attention. . $^{11,13,14}$

In angiographical analyses, Bowles and Daves noticed that the minor artery branches off directly from the main septal artery. It directs its course through the whole length of the trabecula and the anterior papillary muscle, and is anchored in the anterior leaflet of the tricuspid valve. ${ }^{11}$

While describing the visualization of all arteries with a diameter over $200 \mu \mathrm{m}$ in coronarography, Pawlak stated that the artery of the SMT was often visible. ${ }^{14}$ Bowles and Daves confirmed its presence in 34 out of 36 septomarginal trabeculae in children's hearts and in 26 out of 36 adult hearts. ${ }^{11}$

Our research indicates that the artery of the SMT is the most developed among all the arteries passing through the SMT. At times, there are several major vessels present, but it is always larger than the rest (Fig. 4, 5). However, Kosiński and Grzybiak observed 2 arterioles of different size in 5 out of the 10 examined trabeculae. ${ }^{15}$

In our material, in the most numerously represented morphological types of the SMT, an initial increase in the area of the cross-section of both the artery of the trabecula and all arterial vessels altogether was noticed. In the case of the artery of the trabecula, this parameter increased up to half of the length of the SMT, and then decreased toward its end. In type III, the vessel was characterized on average by the same section as at the beginning of the trabecula; however, it was smaller in type IV at the end of the artery (Tables 2,3). The total area of the section of all vessels in both types was also larger in the middle part of the trabecula; at the same time, it turned out to be larger at the end rather than at the beginning of the trabecula (Tables 4,5 ).

It may be concluded that the reduction of the area of the cross-section of the artery toward the end of the SMT is compensated by an increase in the area of the section of smaller vessels, which one by one branch off from the main trunk as it follows its path through the trabecula. This is proved by a statistically significant increase in the number of the arterial vessels observed in subsequent sections through the trabecula (Fig. $6 \mathrm{~A}, \mathrm{~B}$ ), parallel to a reduction of the ratio of the area of the section of all vessels to their number (Fig. 7 A, B).

In conclusion, the artery of the trabecula is reduced in favor of other arteries branching off. In the middle sections, the total area of the sections of the vessels increases, and in the final sections, it is higher than in the initial sections. It may show the role which is performed by the vessels of the trabecula in the blood supply of the anterior papillary muscle. In the discussed morphological types, it is strictly connected with the SMT and the branches of the left coronary artery, which passes through the trabecula and provides the majority of the blood supply for the muscle. 
Another subject of the assessment was the thickness of the muscular layer of the SMT. In each of the morphological types of the SMT, there was an initial increase in the thickness of the muscular layer and a gradual decrease toward the end of the trabecula (Tables 6, 7). Statistical analyses confirmed an increase in the thickness of the muscular layer in the middle levels in types III and IV. Moreover, it was noticeable that the thickness of particular layers of the wall of the artery on the section was variable, but it did not affect the dimensions of the lumen of the vessel. This was similarly described by Lorenz, who noticed that the changes in the thickness of the inner and middle layer did not affect the size of the lumen on the section. This variability seems to be one of the mechanisms of adaptation to exposure to deforming forces. ${ }^{16,17}$ It must be assumed that the middle part of the SMT is more susceptible to deformation. Both the tensing up of muscle fibers and blood ejection during systole of the right ventricle, as well as the relaxation of its muscles during diastole, along with the influence of blood flow, may be the mechanical factors causing a biological response from the walls of the blood vessels in the trabecula.

The ratio of the area of the cross-section of the muscular layer of the trabecula to the area of the cross-section of the whole SMT artery was similar in all types: it increased on the whole length of the trabecula (Tables 8, 9). Statistical grouping analyses confirm the importance of this tendency (Fig. 8 A, B). Taking into consideration that both the areas of the cross-section of the artery of the trabecula and its muscular layer decrease from the middle levels toward the end of the trabecula, it can be assumed that the muscular layer takes relatively more area of the cross-section of the whole artery toward the anterior papillary muscle. This may be related to the fact that in the area where the trabecula and the anterior papillary muscle are connected with the anterior wall of the right ventricle there are particularly intensive tensions during systole, which determine the thickness of the muscles of the blood vessels.

This study shows that the arteries of the SMT, which are in close connection with the anterior papillary muscle, supply it with blood when they reach it. Furthermore, the structure of the vessels of the trabecula may also form a crucial component of the blood supply of the free part of the anterior-lateral wall of the right ventricle. Similar data can be found in the literature. ${ }^{3,7,9}$ According to many authors, properly-shaped vessels of the trabecula may create anastomoses between the system of the left and right coronary artery.

The analyses of Reig-Vilallonga et al. confirmed the presence of anastomoses in $96 \%$ of the examined cases, including the anastomoses within the supraventricular crest, where the SMT was created in $76 \%$ of the cases. Moreover, they distinguished 4 types. ${ }^{18}$ In their previous study, they confirmed the existence of anastomoses in $68.1 \%$ of cases. ${ }^{19}$ The results of the study we conducted also confirm the presence of such arterial connections - on the anterior wall of the right ventricle and on the base of the anterior papillary muscle.

The authors of numerous works show the protective role of the blood flow to the muscle of the right ventricle through the arteries of the SMT. ${ }^{3,20-26}$ The research suggests that myocardial infarction of the right ventricle is caused by the narrowing of the proximal section of the right coronary artery, especially of the abovementioned artery of the trabecula. ${ }^{22}$ When the vessel is unobstructed in the anterior-lateral part of the free wall of the right ventricle, ischemic damages occur less frequently. ${ }^{3,27}$ Haupt et al. described 19 cases of acute myocardial infarction of the anterior-lateral wall of the right ventricle as a result of the closure of the lumen of the section proximal to the right coronary artery. In 5 patients who had an extensive (>25\%) myocardial infarction of the right ventricle, 4 had a significant $(>75 \%)$ narrowing of the anterior left descending artery (proximal to the beginning of the artery of the SMT), 2 had a closure of the $1^{\text {st }}$ septal branch of this artery, and 1 had coronary thrombosis in the initial part of the right coronary artery. The authors observed a positive correlation between the extension of myocardial infarction of the ventricle and some degree of impairment of a potential collateral flow from the anterior left descending artery to the right coronary artery. ${ }^{22}$

Other researchers have described a clinical situation in which myocardial infarction affected the left ventricle of the heart and until the moment of total closure of the lumen of the left coronary artery, the collateral circulation path was provided by the arteries of the SMT, but in the opposite direction. In the postmortem coronography, they noticed a well-developed artery in the SMT. ${ }^{5}$

In conclusion, the passing of the septomarginal trabecula through the lumen of the right ventricle exposes its arteries to the influence of factors which may evoke a biological response from the walls of this vessel, causing the thickening of the muscular layer and, as a result, of the cross-section of the whole artery, in the middle sections. Moreover, in the final sections of the SMT, the muscular layer of its artery gradually takes up more and more area of the cross-section of the whole vessel.

\section{References}

1. Kosiński A, Kozłowski D, Nowiński J, Lewicka E, Dąbrowska-Kugacka A. Morphogenetic aspects of the septomarginal trabecula in the human heart. Arch Med Sci. 2010;6:733-743.

2. The R Core Team. R: A Language and Environment for Statistical Computing. Vienna: R Foundation for Statistical Computing; 2012.

3. Farrer-Brown G. Vascular pattern of myocardium of right ventricle of human heart. Br Heart J. 1968;30:679-686.

4. Melo JQ, Abecassis M, Neves J, et al. Can the location of the large septal artery be predicted? Eur J Cardio-Thoracic Surg. 1995;9:628-630.

5. Pyda M, Grajek S. Ramus limbi dextri or 'moderator band' artery. Kardiol Pol. 1991;34:26-29.

6. Reig J, Alberti N, Petit M. Arterial vascularization of the human moderator band: An analysis of this structure's role as a collateral. Clin Anat. 2000;13:244-250.

7. Dobyns BM. Note on an artery of the moderator band. Anat Rec. 1936;66:397-400. 
8. Minne I, Depreux R, Mestdagh H, Houcke M. Arterial vascularization of the moderator band (septomarginal trabecula). Lille Med. 1975;20:478-480.

9. Fitzgerald D, Lazzara R. Functional anatomy of the conduction system. Hosp Pract. 1988;23:81-92.

10. Jacobs JE. Computed tomographic evaluation of the normal cardiac anatomy. Radiol Clin North Am. 2010;48:701-710.

11. Bowles CR, Daves ML. Ramus limbi dextri: Demonstration by coronary angiography. Radiology. 1985;155:574.

12. Gross L. The Blood Supply to the Heart in its Anatomical and Clinical Aspects. New York, NY: Paul B. Hoeber; 1921.

13. Miller SW, ed. Cardiac Angiography. Boston: Little Brown and Company; 1984

14. Pawlak B. Krążenie oboczne w miażdżycy tętnic wieńcowych. Pol J Radiol. 1979;43:161-164.

15. Kosiński A, Grzybiak M. The blood supply of the septomarginal trabecula in the hearts of elder people. Geriatria. 2010;4:237-241.

16. Lorenz G, Guski H. Histotopographic and morphometric studies of the intramural coronary arteries in the trabecula septomarginalis of swine and pigmy goats. Z Allg Pathol und Pathol Anat. 1990;136:87-95 [in German].

17. Lorenz G. Histotopographical studies of the intramural coronary arteries into the trabecula septomarginalis of the right cardiac ventricle in pig (Sus scrofa domesticus) and pygmy goat (Capra aegagrus f. domestica). Z Mikrosk Anat Forsch. 1990;104:607-616 [in German].
18. Reig-Vilallonga J, Loncan-Vidal MP, Domenech-Mateu JM. Coronary arterial anastomoses study of their distribution in adult hearts specially emphasizing the crista supraventricularis area. Anat Anz. 1987;164:1-12 [in German].

19. Reig-Vilallonga J, Loncan-Vidal MP, Domenech-Mateu JM. Study of the coronary artery branches to the crista supraventricularis. Bull Assoc Anat. 1983;67:337-345.

20. Cohn JN, Guiha NH, Broder MI, Limas CJ. Right ventricular infarction: Clinical and hemodynamic features. Am J Cardiol. 1974;33:209-214.

21. Dwyer EM, Coquia S, Greenberg H, Pinkernell BH. Inferior myocardial infarction and right coronary artery occlusive disease: A correlative study. Br Heart J. 1975;37:464-470.

22. Haupt HM, Hutchins GM, Moore GW. Right ventricular infarction: Role of the moderator band artery in determining infarct size. Circulation. 1983;67:1268-1272.

23. Laurie W, Woods JD. Infarction (ischaemic fibrosis) in the right ventricle of the heart. Acta Cardiol. 1963;399-411.

24. Ratliff NB, Hackel DB. Combined right and left ventricular infarction: Pathogenesis and clinicopathologic correlations. Am J Cardiol. 1980:45:217-221.

25. Rotman M, Ratliff NB, Hawley J. Right ventricular infarction: A haemodynamic diagnosis. Br Heart J. 1974;36:941-944.

26. Wade WG. The pathogenesis of infarction of the right ventricle. Br Heart J. 1959;21:545-54.

27. Luciano DS, Vander AI, Sherman JH. Human Function and Structure. New York, NY: McGraw-Hill Companies; 1978. 